\title{
Client-provider interactions in provider-initiated and voluntary HIV counseling and testing services in Uganda
}

Rhoda K Wanyenze ${ }^{1 *}$, David Kyaddondo ${ }^{2}$, John Kinsman ${ }^{3}$, Fredrick Makumbi ${ }^{1}$, Robert Colebunders ${ }^{4}$ and Anita Hardon ${ }^{5}$

\begin{abstract}
Background: Provider-initiated HIV testing and counselling (PITC) is based on information-giving while voluntary counselling and testing (VCT) includes individualised client-centered counseling. It is not known if the providerclient experiences, perceptions and client satisfaction with the information provided differs in the two approaches.

Methods: In 2008, we conducted structured interviews with 627 individuals in Uganda; 301 tested through PITC and 326 through voluntary counselling and testing (VCT). We compared client experiences and perceptions based on the essential elements of consent, confidentiality, counseling, and referral for follow-up care. We conducted multivariate analysis for predictors of reporting information or counselling as sufficient.

Results: In VCT, 96.6\% (282) said they were asked for consent compared to 91.3\% (198) in PITC (P=0.01). About the information provided, $92.0 \%$ (286) in VCT found it sufficient compared to $78.7 \%$ (221) in PITC ( $P=<0.01)$. In VCT $79.9 \%$ (246) thought their results were kept confidential compared to $71.7 \%(200)$ in PITC ( $P=0.02)$. Eighty percent (64) of HIV infected VCT clients said they were referred for follow-up care versus $87.3 \%$ (48) in PITC $(p=0.2)$.

Predictors of perceived adequacy of information in PITC included an opportunity to ask questions (adj.RR 1.76, $\mathrm{Cl} 1.41,2.18$ ) and expecting the test results received (adj.RR 1.18, Cl 1.06, 1.33). For VCT significant factors included being given an opportunity to ask questions (adj.RR 1.62, Cl 1.00, 2.60) and 3+ prior times tested, (adj.RR 1.05, Cl 1.00, 1.09).

Conclusions: This study demonstrates good practices in the essential elements of HIV testing for both VCT and PITC. However, further quality enhancement is required in both testing approaches in relation to referral to HIV care post-test, client confidence in relation to confidentiality, and providing an opportunity to ask questions to address client-specific information needs.
\end{abstract}

\section{Background}

HIV counselling and testing (HCT) is critical to the expansion of access to HIV prevention, care and treatment services [1]. In addition to several emerging prevention tools, treatment as prevention has gained prominence with introduction of life-long treatment for HIV infected pregnant women and increasing CD4 cut-off for initiation of antiretroviral treatment for adults and adolescents [2-5]. All these interventions are hinged on large

\footnotetext{
* Correspondence: rwanyenze@hotmail.com

${ }^{1}$ Department of Disease Control and Environmental Health, Makerere University School of Public Health, P.O. Box 7072, Kampala, Uganda Full list of author information is available at the end of the article
}

scale testing to identify and treat people who are HIV infected in order to reduce the risk of HIV transmission.

In order to scale up access to HCT alternative approaches to HCT including home-based and providerinitiated HIV testing and counselling (PITC) have been widely adopted in many countries [6-9]. Several studies and systematic reviews show increased uptake of HCT and access to services following introduction of PITC [10-12]. In Uganda PITC was adopted in 2005 with a focus on diagnosing and linking HIV infected individuals to care and treatment $[9,12]$. Counseling pre-test was reduced to introducing the HIV test and explaining the patient's right to opt-out as well as options for care if they are HIV infected. Pre-test counseling on risk-

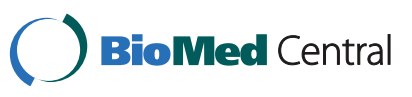


reduction was no longer required [13]. The didactic post-test session highlights prevention options, disclosure and partner testing [13]. On the other hand, the VCT protocol continues to demand detailed clientcentered HIV risk assessment and risk reduction counseling before and after the test [9].

Consent, confidentiality, adequate counseling or information, and referral for other relevant services post-test are critical elements of good quality HCT. There are clear differences between VCT and PITC however, ensuring quality of HCT services irrespective of the approach remains critical. The aim of this study was to compare the client experiences and perceptions of quality as well as satisfaction with counseling or information provided in VCT and PITC.

We conducted structured interviews with clients tested through VCT and PITC in Uganda, and compared their experiences and perceptions of consent, counselling and confidentiality. This study was done as part of the Multi-Country African Study on Testing and Counselling for HIV (MATCH) which investigated HIV testing and counselling practices and experiences in four African countries: Burkina Faso, Kenya, Malawi, and Uganda [14]. The study was approved by the Makerere University Child Health Development Center Ethics Committee and the Uganda National Council for Science and Technology.

\section{Methods}

Between May and December 2008, we conducted structured client interviews with 627 adults ( $\geq 18$ years) including 301 tested through PITC and 326 tested through VCT.

\section{Study sites}

At the time of conducting this study, PITC (outside PMTCT) in Uganda was implemented largely with support from Mulago-Mbarara Teaching Hospitals' Joint AIDS Program (MJAP) and Research Triangle International (RTI). We selected facilities supported by each of the two programs. The selected sites included the national referral and teaching hospital (Mulago Hospital), a regional referral hospital (Soroti Hospital) and a level IV Health Centre (Mpigi Health Center). All the three sites had implemented PITC for over two years. For VCT, we selected the largest and longest VCT provider in Uganda (AIDS Information Center), including an upcountry site in Soroti and another in the capital city of Kampala.

\section{Selection of respondents}

Within the health facilities patients were selected from medical and TB wards, out-patient and antenatal clinics. Sampling and selection of respondents varied by site and client load. The Mulago antenatal care (ANC) had many clients, so we selected every 5 th person every clinic day. On the other hand, the wards in the regional referral hospital and HC IV did not have as many patients so all patients who were discharged on any given day were approached for participation. Similarly, all TB patients who were discharged from the wards were approached for participation. For the VCT facilities we selected every 3rd client on a daily basis. Respondents at the VCT sites and PITC outpatient clinics were approached for participation in the waiting area but interviews were conducted after their session with the providers (on exit from the clinics). Inpatients were approached and interviewed immediately after discharge from the wards.

All respondents provided written consent for participation (signature or thumb print). Out of 303 individuals who were approached within PITC, all agreed to be interviewed but two did not complete the interview. Out of 340 VCT clients who were approached for participation, 4 declined and 10 who had initially agreed to participate did not complete the interview. The major reason for decline and failure to complete interviews was lack of time. Clients were rushing home after being discharged or getting their HIV results.

\section{Measures}

The structured interviews elicited information on client experiences with consent and counseling and perceptions of confidentiality of their test results.

Measures of consent were: whether providers asked clients for consent before testing, and whether providers informed them that they had a right to agree or decline testing.

In addition, we asked whether the PITC clients thought it was important to be given a chance to consent before testing. Measures for confidentiality were: whether providers told clients that their test results would be kept confidential, and clients' perceptions of whether they felt their results would be kept confidential. In terms of adequacy of counselling, we used a standardised protocol of information that should be given during pre- and post-test counselling based on the Uganda national VCT protocol which includes: how HIV is transmitted; how the test works; the meaning of positive and negative results; explanation of the window period; information on prevention, disclosure and partner testing. In terms of overall perceived quality of the counselling and testing services, we asked if the clients felt the information they had received was sufficient, whether they were given an opportunity to ask questions, how they were treated by providers, and if they found the interaction with the providers useful. The same questions were asked of respondents in PITC and stand-alone VCT. 


\section{Data analysis}

We compared experiences across the two strategies and used chi-square tests to test for differences across the two groups. Within PITC we conducted a sub-analysis and comparisons of respondents including in ANC, medical inpatients, and outpatients. TB inpatients were combined with other medical inpatients since the number of TB inpatients interviewed was small $(<30)$. We conducted bivariate and multivariate analysis for factors associated with perceived adequacy of information or counseling. We assumed that there would be differences by age, marital status, educational level and sex; and also by HIV sero-status, whether clients expected the results they received and if they were given an opportunity to ask questions. The outcome variable for the bivariate and multivariate analysis was proportion of clients reporting that information received was sufficient. Because of the inherent differences in testing approach between VCT (client-initiated) and PITC (provider-initiated), we developed separate models for PITC and VCT. The model of choice was a generalized linear model (GLM) with the binomial family and a log link regression but because of convergence problems with this model, we opted for a "modified" Poisson model (under GLM with Poisson family and log link with robust standard errors with out exposure offset) and adjusted for clustering at geographical location of health facility (Soroti, Mulago/Kampala and Mpigi) to obtain prevalence risk ratio (RR) of reporting that information provided was sufficient[15]. In the multivariate analysis, we included variables from the bivariate analysis with p-value $<0.15$ or potential confounders. Statistical analyses were performed using Stata ${ }^{\text {тм }}$ Release 9.2 (Stata Corporation, 4905 Lakeway Drive, College Station, Texas 77845 USA).

\section{Results}

More respondents were women than men: $53.4 \%$ (174) in VCT and 62.1\% (187) in PITC. VCT respondents were more often never married, $44.8 \%$ (145) compared to $18.4 \%$ (55) in PITC, $\mathrm{p}<0.0001$; and a larger proportion of respondents in VCT, 50.3\% (157) were first-time testers compared to $39.0 \%$ (112) in PITC (Table 1).

\section{Consent process}

The majority of respondents in VCT $(82.3 \%, 256)$ and PITC $(83.9 \%, 239)$ said they did not find it difficult to decide to be tested. The majority of respondents also reported that they were asked if they agreed to be tested; significantly higher in VCT, 96.6\% (282) than PITC, $91.3 \%$ (198), $(p=0.01)$. A lower proportion said they were told about their right to decline testing; again this measure of consent was higher in VCT, 89.7\% (262) than PITC, 80.1\% (173), $(\mathrm{p}=0.002)$. All respondents who
Table 1 Socio-demographic characteristics of respondents

\begin{tabular}{|c|c|c|c|}
\hline Respondent characteristics & $\begin{array}{c}\text { Total } \\
\mathrm{N}=627\end{array}$ & $\begin{array}{c}\text { VCT N (\%) } \\
\mathrm{N}=326\end{array}$ & $\begin{array}{c}\text { PITC N (\%) } \\
\mathrm{N}=\mathbf{3 0 1}\end{array}$ \\
\hline \multicolumn{4}{|l|}{ Age } \\
\hline Mean (SD) & $31.26(10.72)$ & $30.2(8.85)$ & $32.5(12.36)$ \\
\hline Median (IQR) & $29(24,37)$ & $28(24,35)$ & $29(24,38)$ \\
\hline \multicolumn{4}{|l|}{ Age-group } \\
\hline $18-20$ & $76(12.2)$ & $40(12.3)$ & $36(12.0)$ \\
\hline $21-30$ & $302(48.3)$ & $162(49.7)$ & $140(46.8)$ \\
\hline $31-40$ & $151(24.2)$ & $81(24.9)$ & $70(23.4)$ \\
\hline $41-50$ & $58(9.3)$ & $33(10.1)$ & $25(8.4)$ \\
\hline $50+$ & $38(6.1)$ & $10(3.1)$ & $28(9.4)$ \\
\hline \multicolumn{4}{|l|}{ Sex } \\
\hline Female & $361(57.6)$ & $174(53.4)$ & $187(62.1)$ \\
\hline Male & $266(42.4)$ & $152(46.6)$ & $114(37.9)$ \\
\hline \multicolumn{4}{|l|}{ Education } \\
\hline No formal education & $39(6.3)$ & $21(6.5)$ & $18(6.0)$ \\
\hline Primary & $226(36.2)$ & $79(24.3)$ & $147(49.2)$ \\
\hline Secondary/vocational & $282(45.2)$ & $166(51.1)$ & $116(38.8)$ \\
\hline Post-secondary & $71(11.3)$ & $56(17.2)$ & $15(5.0)$ \\
\hline Other & $6(1.0)$ & $3(1.0)$ & $3(1.0)$ \\
\hline \multicolumn{4}{|l|}{ Marital status } \\
\hline Never married & $200(32.1)$ & $145(44.8)$ & $55(18.4)$ \\
\hline Married or cohabiting & $327(52.5)$ & $129(39.8)$ & $198(66.2)$ \\
\hline Divorced/separated & $55(8.8)$ & $27(8.3)$ & $28(9.4)$ \\
\hline Widowed & $41(6.6)$ & $23(7.1)$ & $18(6.0)$ \\
\hline \multicolumn{4}{|l|}{ Religion } \\
\hline Catholic & $205(32.7)$ & $89(27.3)$ & $116(38.5)$ \\
\hline Protestant & $222(35.4)$ & $127(39.0)$ & 95 (31.6) \\
\hline Moslem & $102(18.3)$ & $62(19.0)$ & $40(13.3)$ \\
\hline Pentecostal & $84(13.4)$ & $41(12.6)$ & $43(14.3)$ \\
\hline SDA & $14(2.2)$ & $7(2.2)$ & $7(2.3)$ \\
\hline \multicolumn{4}{|l|}{ Previous HIV testing } \\
\hline Once & $269(44.9)$ & $157(50.3)$ & $112(39.0)$ \\
\hline Twice & $137(22.9)$ & $57(18.3)$ & $80(27.9)$ \\
\hline Thrice & $193(32.2)$ & $98(31.4)$ & $95(33.1)$ \\
\hline
\end{tabular}

were asked for consent said they agreed to be tested except one in VCT and nine in PITC who said they did not know. When PITC respondents were asked how important it was for them to agree or decline to be tested majority $(65.5 \%, 116)$ said it was very important, $20.3 \%$ (36) said it was somewhat important while the rest thought it was not important.

\section{Receipt of results and confidentiality}

Almost all respondents reported that they had received their results; $99.4 \%$ (313) in VCT and 97.2\% (280) in 
Table 2 Client perceptions of the confidentiality, counselling and consent procedures within VCT and PITC

Client perceptions/experiences

Asked if they agreed to test

Yes

No

Explained choice to decline test

Yes

No

Told that results would remain confidential

Yes

No

Explained HIV transmission

Yes

No

Explained how the test works

Yes

No

Explained + ve/-ve results

Yes

No

Explained window period

Yes

No

Given advice on prevention

Yes

No

Explained meaning of results

Yes

No

\section{Discussed disclosure}

Yes

No

Discussed prevention

Yes

No

Referral for medical care

Yes

No

Information given sufficient

Yes

No

Do not know
Total $\mathrm{N}=627$

VCT N $=326$

PITC N = 301

Chi square ( $p$ value)

Pre-test session

480 (94.3)

282 (96.6)

198 (91.2)

$29(5.7)$

10 (3.4)

19 (8.8)

0.010

435 (85.6)

262 (89.7)

173 (80.1)

0.002

73 (14.4)

$30(10.3)$

$43(19.9)$

459 (90.2)

274 (93.8)

185 (85.3)

48 (9.4)

16 (5.5)

32 (14.8)

0.001

456 (89.6)

267 (91.4)

189 (87.1)

52 (10.2)

24 (8.2)

28 (12.9)

0.159

365 (71.9)

212 (72.6)

$153(70.8)$

143 (28.2)

80 (27.4)

63 (29.2)

0.661

461 (91.3)

268 (92.7)

193 (89.4)

44 (8.7)

$21(7.3)$

23 (10.7)

0.182

421 (82.7)

252 (86.3)

169 (77.9)

85 (16.7)

39 (13.4)

46 (21.2)

0.071

483 (94.9)

281 (96.2)

202 (93.1)

26 (5.1)

$11(3.8)$

$15(6.9)$

0.111

Post-test session

569 (96.0)

309 (99.0)

260 (92.5)

$21(3.5)$

$3(1.0)$

$18(6.4)$

0.001

395 (66.6)

221 (70.8)

$174(61.9)$

193 (32.6)

90 (28.9)

103 (36.7)

0.076

537 (90.6)

302 (96.8)

235 (83.6)

51 (8.6)

10 (3.2)

41 (14.6)

$<0.001$

112 (83.0)

$64(80.0)$

48 (87.3)

23 (17.0)

16 (20.0)

7 (12.7)

Overall session (Perceived quality)

$507(85.6)$
$57(9.6)$
$25(4.2)$

286 (92.0)

221 (78.7)

$25(4.2)$

$15(4.8)$

$42(15.0)$

$<0.001$

$16(5.7)$ 
Table 2 Client perceptions of the confidentiality, counselling and consent procedures within VCT and PITC (Continued)

\begin{tabular}{|c|c|c|c|c|}
\hline \multicolumn{5}{|c|}{ Felt results were kept confidential } \\
\hline Yes & $446(76.0)$ & $246(79.9)$ & $200(71.7)$ & \\
\hline No & $10(1.7)$ & $2(0.7)$ & $8(2.9)$ & 0.020 \\
\hline Don't know & $131(22.3)$ & $60(19.5)$ & $71(25.5)$ & \\
\hline \multicolumn{5}{|c|}{ Opportunity to ask questions } \\
\hline Yes & $498(84.4)$ & $297(96.1)$ & $201(71.5)$ & \\
\hline No & $85(14.4)$ & $12(3.9)$ & $73(26.0)$ & $<0.001$ \\
\hline \multicolumn{5}{|c|}{ How they were treated by providers } \\
\hline Very well & $243(41.0)$ & $144(46.2)$ & $99(35.2)$ & 0.021 \\
\hline Well & $337(56.8)$ & $167(53.6)$ & $170(60.5)$ & \\
\hline badly & $5(0.8)$ & $1(0.3)$ & $4(1.4)$ & \\
\hline Declined to answer & $8(1.4)$ & $0(0)$ & $8(2.9)$ & \\
\hline \multicolumn{5}{|c|}{ Expected results they received } \\
\hline Yes & $336(57.2)$ & $188(60.8)$ & $148(53.2)$ & \\
\hline No & $216(36.8)$ & $111(35.9)$ & $105(37.8)$ & 0.017 \\
\hline Don't know & $33(5.6)$ & $9(2.9)$ & $24(8.6)$ & \\
\hline
\end{tabular}

PITC $(\mathrm{P}=0.1)$. However three VCT respondents declined to share their results. Among those who shared their results, $27.0 \%$ (88) in VCT and 20.1\% (56) in PITC said they were HIV infected. Within PITC 26.9\% inpatients reported that they were HIV positive compared to $16.9 \%$ outpatients and $14.5 \%$ in ANC. A significant proportion of the respondents said they were not expecting the results they received in terms of the HIV sero-status; $36.0 \%(111)$ in VCT and 37.8\% (105) in PITC $(\mathrm{P}=0.05)$.

The majority of the clients were told by providers that their results would be kept confidential; 94.5\% (274) in VCT compared to $85.3 \%(185)$ in PITC $(\mathrm{P}=0.007)$. Asked whether they felt their results had been protected so that nobody else knows them, the majority agreed; $79.9 \%$ (246) in VCT versus $71.7 \%(200)$ in PITC $(\mathrm{P}=0.02)$. A significant proportion of the clients said they did not know whether this had happened; 19.5\% (60) in VCT and 25.5\% (71) in PITC. In terms of whether the clients thought confidentiality was important, $73.1 \%$ (228) in VCT agreed compared to $67.6 \%(188)$ in PITC $(\mathrm{P}=0.5)$.

\section{Pre- and post-test counselling}

The majority of respondents in VCT and PITC received pre-test information on how HIV is transmitted, how the test works, the meaning of positive and negative results, explanation of the window period, and information on prevention, and we did not detect any significant differences by strategy (Table 2). During the post-test session, they received the same information but the PITC were less likely to receive the information (Table 2). A high proportion of respondents across both strategies said the information they received was sufficient but this was significantly lower in PITC; 92.0\% (286) in VCT versus $78.7 \%$ (221) in PITC ( $\mathrm{P}=<0.001)$. About the opportunity to ask questions, 96.1\% (297) in VCT agreed compared to $71.5 \%$ (201) in PITC ( $<<0.001)$. On how useful the meeting with the providers was, $99.4 \%$ (307) in VCT said it was useful compared to $86.8 \%$ (244) in PITC $(\mathrm{p}<0.001)$. The majority of respondents said they were treated well by the providers (Table 2). Eighty percent (64) of the HIV infected individuals in VCT and 87.3\% (48) from PITC said they were referred for followup care $(\mathrm{p}=0.3)$.

\section{Experiences of antenatal, inpatients and outpatients}

Within PITC the experiences of patients were similar across the clinics and wards but there were differences for some parameters. All (73) the ANC and almost all the inpatients $(95.5 \%, 70)$ reported that they had been asked if they agreed to test compared to $77.0 \%$ (52) of the outpatients. A higher proportion in ANC $(94.1,80)$ reported receiving HIV prevention information compared to inpatients $(81.4 \%, 83)$ and outpatients $(79.8 \%, 67)$. Similarly, a higher proportion in ANC $(88.3 \%, 75)$ reported receiving information on partner testing compared to inpatients $(76.5 \%, 78)$ and outpatients $(78.6 \%, 66)$. Among ANC clients, 98.6\% (72) reported that they were given an opportunity to ask questions, compared to $90.3 \%$ of inpatients and $89.7 \%$ (62) of outpatients. A lower proportion across all the three categories of patients reported that the information they received was sufficient; $86.6 \%$ (71) in ANC compared to $80.0 \%(80)$ of inpatients and $86.8 \%$ (66) of outpatients.

\section{Predictors of sufficient information or counselling} In the bivariate analysis for PITC, individuals who received results that they expected were more likely to find 
the information sufficient (RR 1.21, CI 1.06-1.37). Also, individuals who were given an opportunity to ask questions were more likely to find the information sufficient (RR 1.73, CI 1.39-2.16). There were no significant differences by type of patients (ANC, inpatients and outpatients), number of previous HIV tests, HIV sero-status, gender and age (Table 3). In the multivariate analysis for PITC, significant predictors of information being sufficient included being given an opportunity to ask questions (adj.RR 1.73, CI 1.43-2.10) and expecting the results they received (adj.RR 1.07, CI 1.01-1.14). Individuals who had previously tested for HIV once or twice were less likely to report that the information was sufficient while those who had tested three or more times were not significantly different from those who were testing for the first time (Table 3).
Within VCT, receiving results that they expected and being given an opportunity to ask questions were not significantly associated with information being sufficient at bivariate analysis (Table 4). There were also no significant differences by HIV sero-status, gender and age. However the number of previous HIV tests was significant; individuals who had previously tested for HIV once or twice were less likely to find the information sufficient while those who had previously tested for three or more times were more likely to find the information sufficient (Table 4). In the multivariate analysis for VCT, significant predictors of information being sufficient included being given an opportunity to ask questions (adj.RR 1.62, CI 1.00-2.60) and the number of previous tests (Table 4).

Table 3 Proportion, crude and adjusted risk ratio for association between reporting that counseling information was sufficient by PITC respondent's characteristics

\begin{tabular}{|c|c|c|c|c|c|}
\hline & Total respondents & $\begin{array}{c}\text { Number reporting } \\
\text { information was sufficient }\end{array}$ & $\begin{array}{c}\text { Percentage reporting } \\
\text { information was sufficient }\end{array}$ & $\begin{array}{l}\text { Crude risk } \\
\text { ratio }(95 \% \mathrm{Cl})\end{array}$ & $\begin{array}{l}\text { Adjusted risk } \\
\text { ratio }(95 \% \mathrm{Cl})\end{array}$ \\
\hline & $\mathrm{N}$ & 'n & $100,(\%)$ & & \\
\hline Overall & 265 & 213 & 80.4 & & \\
\hline \multicolumn{6}{|l|}{ Age (years) } \\
\hline $18-20$ & 32 & 29 & 90.6 & 1.0 & \\
\hline $21-30$ & 128 & 103 & 80.5 & $0.89(0.79,0.997)$ & \\
\hline $31-40$ & 63 & 48 & 76.2 & $0.84(0.67,1.06)$ & \\
\hline $41-50$ & 21 & 17 & 81.0 & $0.89(0.75,1.06)$ & \\
\hline $51+$ & 21 & 16 & 76.2 & $0.84(0.62,1.14)$ & \\
\hline \multicolumn{6}{|l|}{ Sex } \\
\hline Female & 166 & 134 & 80.7 & 1.0 & 1.0 \\
\hline Male & 99 & 79 & 79.8 & $0.99(0.85,1.15)$ & $1.00(0.85,1.17)$ \\
\hline \multicolumn{6}{|l|}{ Times tested for HIV } \\
\hline 1 & 103 & 86 & 83.5 & 1.0 & 1.0 \\
\hline $2-3$ & 124 & 96 & 77.4 & $0.93(0.77,1.12)$ & $0.88(0.83,0.94)$ \\
\hline $4+$ & 38 & 31 & 81.6 & $0.98(0.76,1.25)$ & $0.99(0.76,1.30)$ \\
\hline \multicolumn{6}{|l|}{ Test results expected } \\
\hline No/do not know & 123 & 89 & 72.4 & 1.0 & 1.0 \\
\hline Yes & 142 & 124 & 87.3 & $1.21(1.16,1.25)$ & $1.18(1.10,1.28)$ \\
\hline \multicolumn{6}{|l|}{ Reported HIV status } \\
\hline Negative/Indeterminate & 211 & 169 & 80.1 & 1.0 & 1.0 \\
\hline Positive & 54 & 44 & 81.5 & $1.02(0.84,1.23)$ & $0.96(0.83,1.12)$ \\
\hline \multicolumn{6}{|l|}{ Opportunity to ask } \\
\hline No/do not know & 74 & 39 & 52.7 & 1.0 & 1.0 \\
\hline Yes & 191 & 174 & 91.1 & $1.73(1.52,1.96)$ & $1.76(1.43,2.16)$ \\
\hline \multicolumn{6}{|l|}{ Type of Facility } \\
\hline ANC & 83 & 70 & 84.3 & 1.0 & 1.0 \\
\hline In-patient & 101 & 78 & 77.2 & $1.05(0.77,1.44)$ & $0.93(0.67,1.30)$ \\
\hline OPD & 81 & 65 & 80.2 & $0.96(0.80,1.15)$ & $0.96(0.82,1.17)$ \\
\hline
\end{tabular}


Table 4 Proportion, crude and adjusted risk ratio for association between reporting that counseling information was sufficient by VCT respondent's characteristics

\begin{tabular}{|c|c|c|c|c|c|}
\hline & Total respondents & $\begin{array}{c}\text { Number reporting } \\
\text { information was sufficient }\end{array}$ & $\begin{array}{c}\text { Percentage reporting } \\
\text { information was sufficient }\end{array}$ & $\begin{array}{l}\text { Crude risk } \\
\text { ratio }(95 \% \mathrm{Cl})\end{array}$ & $\begin{array}{l}\text { Adjusted risk } \\
\text { ratio }(95 \% \mathrm{Cl})\end{array}$ \\
\hline & $\mathrm{N}$ & 'n & $100,(\%)$ & & \\
\hline Overall & 300 & 277 & 92.3 & & \\
\hline \multicolumn{6}{|l|}{ Age (years) } \\
\hline $18-20$ & 33 & 30 & 90.9 & 1.0 & \\
\hline $21-30$ & 149 & 138 & 92.6 & $1.02(0.97,1.07)$ & \\
\hline $31-40$ & 76 & 70 & 92.1 & $1.01(0.996,1.03)$ & \\
\hline $41-50$ & 32 & 29 & 90.6 & $1.00(0.89,1.11)$ & \\
\hline $51+$ & 10 & 10 & 100.0 & $1.10(0.99,1.22)$ & \\
\hline \multicolumn{6}{|l|}{ Sex } \\
\hline Female & 159 & 144 & 90.6 & 1.0 & 1.0 \\
\hline Male & 141 & 133 & 94.3 & $1.04(0.98,1.11)$ & $1.03(0.98,1.08)$ \\
\hline \multicolumn{6}{|l|}{ Times tested for HIV } \\
\hline 1 & 150 & 141 & 94.0 & 1.0 & 1.0 \\
\hline $2-3$ & 98 & 84 & 85.7 & $0.91(0.88,0.94))$ & $0.90(0.89,0.91)$ \\
\hline $4+$ & 52 & 52 & 100.0 & $1.06(0.95,1.18)$ & $1.05(0.94,1.17)$ \\
\hline \multicolumn{6}{|l|}{ Test results expected } \\
\hline No/do not know & 118 & 109 & 92.4 & 1.0 & 1.0 \\
\hline Yes & 182 & 168 & 92.3 & $1.00(0.99,1.00)$ & $0.99(0.98,1.01)$ \\
\hline \multicolumn{6}{|l|}{ Reported HIV status } \\
\hline Negative/Indeterminate & 220 & 205 & 93.2 & 1.0 & 1.0 \\
\hline Positive & 80 & 72 & 90.0 & $0.97(0.95,0.99)$ & $0.96(0.94,0.98)$ \\
\hline \multicolumn{6}{|l|}{ Opportunity to ask } \\
\hline No/do not know & 12 & 7 & 58.3 & 1.0 & 1.0 \\
\hline Yes & 288 & 270 & 93.8 & $1.61(0.95,2.72)$ & $1.62(0.97,2.69)$ \\
\hline
\end{tabular}

\section{Discussion}

These data show good practices in relation to the essential elements of HIV testing in both VCT and PITC. The majority of the PITC respondents thought it was important to decline or accept testing. However, some did not think it was important. This may be associated with the illness and need for diagnosis among PITC respondents and for the ANC the moral issue of protecting the unborn child.

The interaction and information giving within PITC is shorter to enable integration within busy health facilities and it seems to work well for the majority of the patients $[6,9,16,17]$. There were a few individuals in both PITC and VCT who did not find the information adequate. We found that individuals who receive results that they do not expect in PITC need more support than others. The results also indicate that giving the clients an opportunity to ask questions in both VCT and PITC increases the likelihood of finding the information provided to be adequate. This is not surprising because the dialogue would lead to clients raising issues that the providers may overlook and highlights the need to closely examine the practices around information giving to ensure that the patients have an opportunity to raise concerns.

Within VCT an individual has thought about testing and made a deliberate decision to go for the test. For PITC on the other hand, depending on the nature of illness, a patient may come to hospital when they have not thought about HIV testing. This may explain why receiving results that were not expected was more important in PITC than VCT. For home-based HIV testing, another provider-initiated testing strategy, it has been reported that the social mobilization that precedes testing increases acceptance and uptake of testing [18-20]. Social mobilization efforts within countries that have adopted PITC may be necessary to ensure that people are aware and expect PITC when they go to health facilities.

A significant proportion of respondents in both strategies had some doubts about confidentiality. This study did not evaluate why the clients felt this way. However, 
the data highlights the need to address confidentiality concerns among clients.

Although the Ugandan PITC guidelines recommend risk reduction information post-test and not pre-test, to reduce on the time required for $\mathrm{HCT}$, in practice providers gave this information both pre- and post-test and there was little difference between PITC and VCT in the pre-test information.

This study compared clients who were interviewed soon after testing within PITC and VCT. The clients' perceptions of the testing may change over time depending on their coping ability and experiences after the test. However, the study highlights important quality issues that could be improved in both VCT and PITC. Clients who do not get the result that they expect, and those who come for repeat testing may need more attention post-test. Overall clients value being asked whether they have questions.

\section{Conclusions}

Overall, the quality of HCT was good in both strategies, in relation to the essential elements of HIV testing. However, the findings show a need for further quality enhancement in both testing approaches in relation to referral to HIV care post-test, client confidence in relation to confidentiality, and providing an opportunity to ask questions to address client-specific information needs.

\section{Competing interests}

The authors declare that they have no competing interests.

\section{Authors' contributions}

RKW initiated the topic and wrote the first draft of the paper. DK, RC and $\mathrm{AH}$ contributed to the design of the topic, interpretation of findings and writing of the paper. FM analysed the data and contributed to the interpretation of the findings. JK contributed to the interpretation of findings and writing of the paper. All authors read and approved the final manuscript.

\section{Acknowledgments}

This project was supported by a grant from the National Institutes of Health (5 R01 HD053268-05, Pl: Carla Obermeyer). This support is gratefully acknowledged. We acknowledge the contribution of the management of Makerere University Child Health and Development Centre and Mr. Richard Sekiwunga.

\section{Author details}

${ }^{1}$ Department of Disease Control and Environmental Health, Makerere University School of Public Health, P.O. Box 7072, Kampala, Uganda. ${ }^{2}$ Makerere University Department of Social Work/Child Health Development Centre, Kampala, Uganda. ${ }^{3}$ Umeå Centre for Global Health Research, Department of Public Health and Clinical Medicine, Umeå University, Umeå, Sweden. ${ }^{4}$ Institute of Tropical Medicine, Antwerp, Belgium. ${ }^{5}$ University of Amsterdam, Amsterdam, Netherlands.

Received: 1 April 2013 Accepted: 17 October 2013

Published: 19 October 2013

\section{References}

1. World Health Organisation (WHO): Towards universal access: scaling up priority HIV/AIDS interventions in the health sector: progress report 2009. Geneva, Switzerland: WHO; 2008.

2. World Health Organisation: Consolidated guidelines on the use of antiretroviral drugs for treating and preventing HIV infection:
Recommendations for a public health approach; 2013. http://www.who.int/ hiv/pub/guidelines/arv2013/download/en/index.html.

3. Granich RM, Gilks CF, Dye C, De Cock KM, Williams BG: Universal voluntary HIV testing with immediate antiretroviral therapy as a strategy for elimination of HIV transmission: a mathematical model. Lancet 2009, 373(9657):48-57.

4. Dodd PJ, Garnett GP, Hallett TB: Examining the promise of HIV elimination by 'test and treat' in hyperendemic settings. AIDS 2010, 24(5):729-735.

5. Johnston R, Collins C: Can we treat our way out of HIV? AIDS Res Hum Retroviruses 2010, 26(1):1-4.

6. World Health Organisation (WHO): Guidance on provider-initiated HIV testing and counseling in health facilities. Geneva: WHO; 2007

7. Baggaley $R$, Hensen $B$, Ajose $O$, et al: From caution to urgency: the evolution of HIV testing and counselling in Africa. Bull World Health Organ 2012, 90(9):652-8B.

8. Creek TL, Ntumy R, Seipone K, Smith M, Mogodi M, Smit M, et al: Successful introduction of routine opt-out HIV testing in antenatal care in Botswana. J Acquir Immune Defic Syndr 2007, 45(1):102-107.

9. MOH: Uganda National Policy on HIV Counseling and Testing. Kampala, Uganda: Ministry of Health; 2010.

10. Kennedy CE, Fonner VA, Sweat MD, Okero FA, Baggaley R, O'Reilly KR: Provider-initiated HIV testing and counseling in low- and middle-income countries: a systematic review. AIDS Behav 2012, 17:1571-1590. doi: 10.1007/s10461-012-0241-y.

11. Hensen B, Baggaley R, Wong VJ, et al: Universal voluntary HIV testing in antenatal care settings: a review of the contribution of provider-initiated testing \& counselling. Trop Med Int Health 2012, 17(1):59-70.

12. Roura M, Watson-Jones D, Kahawita TM, Ferguson L, Ross DA: Providerinitiated testing and counselling programmes in sub-Saharan Africa: a systematic review of their operational implementation. AIDS 2013, 27(4):617-26.

13. Wanyenze RK, Kamya MR, Fatch R, Mayanja-Kizza H, Baveewo S, Szekeres G, Bangsberg DR, Coates T, Hahn JA: Abbreviated HIV counselling and testing and enhanced referral to care in Uganda: a factorial randomised controlled trial. The Lancet Global Health 2013, 1(3):e137-e145.

14. Obermeyer CM, Neuman M, Desclaux A, Wanyenze R, Ky-Zerbo O, et al: Associations between mode of HIV testing and consent, confidentiality, and referral: a comparative analysis in four African countries. PLoS Med 2012, 10:e1001329.

15. Zou G: A modified poisson regression approach to prospective studies with binary data. Am J Epidemio/ 2004, 159(7):702-706.

16. Wanyenze RK, Nawawu C, Namale AS, Mayanja B, Bunnell R, Abang B, et al: Acceptability of routine HIV counselling and testing, and HIV seroprevalence in Ugandan hospitals. Bull World Health Organ 2008, 86(4):302-9.

17. Menzies N, Abang B, Wanyenze R, Nuwaha F, Mugisha B, Coutinho A, et al: The costs and effectiveness of four HIV counseling and testing strategies in Uganda. AIDS 2009, 23(3):395-401.

18. Were W, Mermin J, Bunnell R, Ekwaru JP, Kaharuza F: Home-based model for HIV voluntary counselling and testing. Lancet 2003, 361(9368):1569.

19. Wolff B, Nyanzi B, Katongole G, Ssesanga D, Ruberantwari A, Whitworth J: Evaluation of a home-based voluntary counselling and testing intervention in rural Uganda. Health Policy Plan 2005, 20(2):109-16.

20. Yoder PS, Katahoire AR, Kyaddondo D, Akol Z, Bunnell R, Kaharuza F: Home-Based HIV Testing and Counselling in a Survey Context in Uganda. Calverton, Maryland, USA: ORC Macro; 2006.

doi:10.1186/1472-6963-13-423

Cite this article as: Wanyenze et al:: Client-provider interactions in provider-initiated and voluntary HIV counseling and testing services in Uganda. BMC Health Services Research 2013 13:423. 